\title{
IMMUNOCYTOCHEMICAL ANALYSIS OF SEROTONERGIC AXONS IN LAMINAE I AND II OF THE LUMBAR SPINAL CORD OF THE CAT
}

\author{
M. A. RUDA, ${ }^{1}$ J. COFFIELD, AND H. W. M. STEINBUSCH* \\ Neurobiology and Anesthesiology Branch, National Institute of Dental Research, National Institutes of Health, \\ Bethesda, Maryland 20205 and ${ }^{*}$ Department of Pharmacology, Free University, Amsterdam, The Netherlands
}

Received April 5, 1982; Accepted May 18, 1982

\begin{abstract}
Serotonergic axons in the superficial dorsal horn were examined at the light and electron microscopic levels using an antibody specific for serotonin (5-HT). Immunoreactive 5-HT axons were most numerous in lamina I and fewest in lamina IIb. The 5-HT axons tended to orient rostrocaudally as they traveled long distances in the gray matter. Based on the size of the 5-HT varicosities along a strand of axon, at least three different types of $5-\mathrm{HT}$ axons were observed at the light microscopic level. Ultrastructurally, 5-HT-immunoreactive axonal endings contained either a mixture of flattened and small oval agranular vesicles or a relatively homogeneous population of oval vesicles. 5-HT endings synapsed primarily on small caliber dendritic shafts. They also were found synapsing on large caliber dendritic shafts, dendritic spines, and neuronal cell bodies. Based on the laminar location of 5-HT axosomatic synapses and the presence of 5-HT synapses on different morphological types of dendrites, we propose that 5 -HT modulates the response properties of at least three different types of neurons in the superficial dorsal horn.
\end{abstract}

Participation of the neurotransmitter serotonin $(5-\mathrm{HT})$ in the modulation of the response of neurons to noxious input has been demonstrated in numerous experimental paradigms (see Dubner and Bennett, 1982; Messing and Lytle, 1977, for a review). Iontophoresis of 5-HT in the dorsal horn typically produces a profound inhibition of the response of neurons to noxious stimulation (Randic and Yu, 1976; Belcher et al., 1978; Jordan et al., 1979; Griersmith and Duggan, 1980), although some spinothalamic tract neurons in the deeper laminae are excited by 5-HT (Jordan et al., 1979). Intrathecal injections of 5-HT produce analgesia (Yaksh and Wilson, 1979) and 5-HT depletion partially blocks stimulation-produced analgesia (Akil and Mayer, 1972) and morphine analgesia (Tenen, 1968). Determination of the site of action of $5-\mathrm{HT}$ is thus crucial to our understanding of the mechanisms of pain and analgesia. 5-HT-containing axonal endings have been characterized ultrastructurally in the medullary dorsal horn of the cat following the uptake of exogenously applied $\left[{ }^{3} \mathrm{H}\right] 5-\mathrm{HT}$ (Ruda and Gobel, 1980). Morphologically similar endings were shown to degenerate after exposure to the 5-HT neurotoxin, 5,6-dihydroxytryptam-

\footnotetext{
${ }^{1}$ To whom correspondence should be addressed at Neurobiology and Anesthesiology Branch, National Institute of Dental Research, National Institutes of Health, Building 30, Room B-20, 9000 Rockville Pike, Bethesda, MD 20205.
}

ine (5,6-DHT) (Ruda and Gobel, 1980). Moreover, the same types of endings were shown to originate in the medial brain stem reticular formation which contains numerous 5-HT neuronal cell bodies (Ruda et al., 1981). 5-HT input was found to occur primarily on dendrites throughout laminae I and II. The presence of 5-HT synapses in these two laminae raises the possibility of multiple sites of action of 5-HT in the dorsal horn. Since the medullary and spinal dorsal horns bear numerous similarities with respect to laminar organization and the morphological types of intrinsic neurons (Gobel et al., 1981a), it is also important to determine if the similarity continues with respect to the location of 5-HT input.

Recent technical advances have produced a well characterized antibody to 5-HT (Steinbusch et al., 1978, 1982) which allows the visualization of 5 -HT axons at the light (Steinbusch, 1981) and electron microscopic levels. The immunocytochemical technique has an advantage over the classical histofluorescence of endogenous 5-HT (Dahlström and Fuxe, 1964, 1965; Fuxe, 1965) in that the marker does not fade, demonstrates superior sensitivity, and can be identified at the ultrastructural level. Immunocytochemistry is preferred to autoradiographical demonstration of 5-HT following the uptake of exogenously applied $\left[{ }^{3} \mathrm{H}\right] 5-\mathrm{HT}$ in that it is possible to see the entire axon, including the intervaricose portion. Autoradiography only reveals isolated aggregates of silver grains which 
overlie sites of the active uptake of $\left[{ }^{3} \mathrm{H}\right]-5 \mathrm{HT}$. Additionally, immunocytochemistry does not require the long exposure times commensurate with autoradiography. This study employs the highly sensitive immunocytochemical technique to characterize 5-HT axons in the lumbar enlargement of the cat spinal cord and compares them with previous observations obtained in the medullary dorsal horn with autoradiography (Ruda and Gobel, 1980).

\section{Materials and Methods}

The immunocytochemical localization of 5-HT was examined in the lumbar spinal cord of six adult cats prepared by intracardiac perfusion with 4 liters of $4 \%$ paraformaldehyde and $0.2 \%$ glutaraldehyde in $0.1 \mathrm{~m}$ phosphate buffer at $\mathrm{pH}$ 7.4. Following the perfusion, the spinal cord was removed, placed in fresh fixative for $2 \mathrm{hr}$ at $4^{\circ} \mathrm{C}$, and subsequently stored in $0.1 \mathrm{M}$ phosphate buffer at $4^{\circ} \mathrm{C}$ overnight. Fifty-micrometer sections for light microscopy (LM) and 100- $\mathrm{m}$ sections for electron microscopy (EM) were cut with a Vibratome in both the transverse and sagittal planes. The sections were processed for immunocytochemistry using the peroxidase-antiperoxidase (PAP) immunocytochemical staining method of Sternberger (1979). Sections were incubated in $1^{\circ}$ antisera at a dilution of $1: 5,000$ to $1: 20,000$ overnight at $4^{\circ} \mathrm{C}$ with gentle agitation. The characteristics of the 5-HT antisera were as previously described (Steinbusch et al., 1978, 1982). Following a rinse in phosphate-buffered saline and $30 \mathrm{~min}$ in $3 \%$ normal goat serum, the sections were incubated sequentially in goat anti-rabbit IgG (1:50) and PAP (1:80, LM; 1:40, EM) (Sternberger-Meyer Immunochemical, Inc.) for $30 \mathrm{~min}$ at room temperature. Tisssue processed for light microscopy was treated with $0.75 \%$ Triton X-100 in the $1^{\circ}, 2^{\circ}$, and PAP incubations, while that used for electron microscopy was not exposed to any penetrating agents. The immunocytochemical reaction product was developed by incubation of the tissue sections in $0.05 \%$ diaminobenzidine hydrochloride (Sigma) and $0.01 \%$ hydrogen peroxide in $0.1 \mathrm{~m}$ phosphate buffer for 6 to $12 \mathrm{~min}$.

For light microscopy, the sections were mounted on gelatin-coated slides and cleared in xylene. Camera lucida drawings of 5-HT axons were made with a Zeiss drawing tube and a $\times 100$ oil immersion lens. Measurements of the size of immunoreactive varicosities were made in the sagittal plane from photographically enlarged drawings of 100- $\mu \mathrm{m}$ lengths of axonal strands at a final magnification of $\times 3,500$. For EM analysis, the tissue was postfixed for $1 \mathrm{hr}$ in $2 \%$ osmium tetroxide in $0.1 \mathrm{M}$ phosphate buffer, dehydrated in a graded series of ethanol, and flatembedded in Epon/Araldite resin (Polysciences, Inc.) on a plastic slide. To reduce the possibility of a sampling error, six different blocks of tissue were examined ultrastructurally. Serial thin sections were cut, collected on Formvar-coated slot grids, and examined with a Zeiss EM 10C electron microscope. Thin sections were examined routinely before and after counterstaining with lead citrate. In unstained sections, the electron-dense PAP reaction product stands out against a pale unlabeled neuropil, permitting observation of lightly labeled structures.

\section{Results}

\section{Light microscopic observations of 5-HT. immunoreactive axonal endings}

Serotonergic axons are found in all laminae of the spinal cord dorsal horn (Fig. 1). Within each lamina, differences can be noted with respect to the density, trajectory, and size of the 5-HT-immunoreactive axons and varicosities. This paper will confine its discussion of 5-HT axons to the superficial dorsal horn, laminae I and II. The data will reflect analysis of 5-HT axons in both the transverse and sagittal planes of the lumbar enlargement.

Transverse plane. In the transverse plane, 5-HT immunoreactivity in laminae I and II of the dorsal horn is observed primarily as isolated, punctate profiles and short strands of 5-HT axons with a few en passant varicosities (Fig. 1, $A$ and $B$ ). Long strands of 5 -HT axons traveling in the transverse plane are observed infrequently in laminae I and II except on the dorsal border of lamina I, beginning at Lissauer's tract. Here, a small bundle of 5-HT axons travels along the top of lamina I, thinning out as it curves along the lateral and medial edges of the dorsal horn (Fig. 1, $A$ and $B$ ). These fibers are particularly noticeable in an area directly medial to Lissauer's tract.

The density of immunoreactive 5- $\mathrm{HT}$ axons is highest in lamina I and decreases slightly in lamina IIa (Fig. $1 B$ ). The ventral part of lamina II, lamina IIb, contains noticeably fewer immunoreactive profiles (Fig. 1B). This density difference is most apparent in the lateral part of the dorsal horn below the root entry zone (Fig. 1A). In the monkey, the decrease in the density of 5-HT input to lamina IIb is even more pronounced than in the cat (M. A. Ruda, unpublished observations).

Islands of neuropil, composed of neuronal cell bodies and dendrites that extend out from lamina I into the overlying white matter, contain dense amounts of 5 -HT. immunoreactive profiles (Fig. 1, $A$ and $C$ ). Isolated 5HT-immunoreactive axons with varicosities are rarely seen in the dorsal fasciculus. When observed, they are located in the ventral part of the dorsal fasciculus, medial to lamina $\mathrm{V}$. The dorsolateral fasciculus contains a few small 5-HT-immunoreactive axons. Some 5-HT axons also are found extending into Lissauer's tract for a short distance (Fig. 1, $A$ and $D$ ). These axons have many varicosities and extend in a dorsoventral direction so as to orient parallel to the incoming primary afferent axons (Fig. $1 D$ ).

Sagittal plane. 5-HT axons in laminae I and II of the dorsal horn can best be observed in the sagittal plane, where a single axon can be followed for several hundred micrometers as it travels rostrocaudally (Fig. 1, C and $D$ ). The 5-HT-immunoreactive axons appear as long strands with numerous boutons en passant. Occasionally, the axons branch and give rise to two long strands which often continue in the same direction as the parent axon (Fig. $2 B$ ). The rostrocaudal orientation of the $5-\mathrm{HT}$ - 

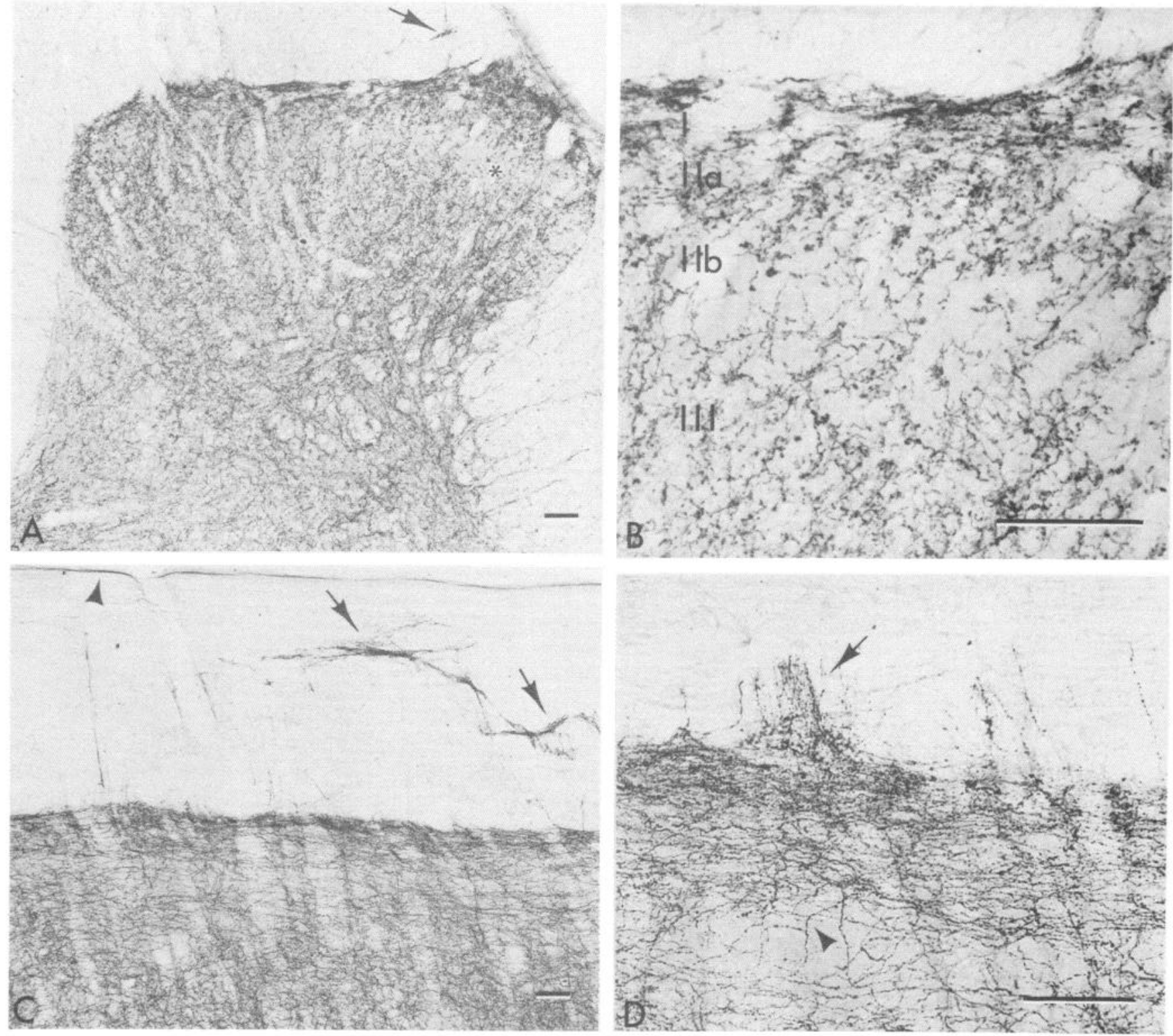

Figure 1. Light microscopic demonstration of immunocytochemically stained 5-HT axons. $A$, Transverse section of the lumbar enlargement of the spinal dorsal horn immunocytochemically stained for 5-HT. Darkly stained 5-HT-immunoreactive axons are found in all laminae of the dorsal horn. Lamina IIb (asterisk) contains noticeably fewer fibers than the other laminae in the dorsal horn. 5-HT-positive fibers also are found in discrete areas of neuropil in the white matter above the dorsal horn (arrow) (see also $C$ ). Magnification $\times 54$. $B$, Higher magnification of the area immediately adjacent to the dorsal root entry zone in $A$. The density of 5-HT-containing axons is highest in lamina I, decreases somewhat in lamina IIa, and is clearly least in lamina IIb. Short strands of 5-HT-immunoreactive axons with numerous bulbous varicosities are observed. Magnification $\times 220 . C$, Sagittal section of the lumbar spinal cord. In addition to the dense fiber plexus within the dorsal horn, bundles of 5-HT-positive axons are found in the overlying white matter (arrows). These 5-HT axons with numerous varicosities orient in the rostrocaudal plane. They appear to innervate the neuronal cell bodies and dendrites which occasionally are found above the dorsal horn proper. This area of gray matter most likely represents displaced portions of lamina I. The surface of the spinal cord is at the top of the illustration (arrowhead). Magnification $\times 54$. D, Higher magnification of a sagittal section of the lumbar spinal cord. 5-HT-immunoreactive axons orient primarily in the rostrocaudal direction. A few axons traverse dorsoventrally in lamina II (arrowhead). Each axon contains numerous darkly stained bulbous varicosities. Some 5-HT axons turn dorsally to enter Lissauer's tract (arrow). In the sagittal plane, individual 5-HT axons can be followed for several hundred micrometers. Magnification $\times 170$. Scale bars, $100 \mu \mathrm{m}$.

containing axons is most striking in lamina I, where many axons with numerous 5 -HT-immunoreactive varicosities position themselves parallel to the dorsal surface of the dorsal horn as they proceed for long distances. In lamina II, the primary orientation of the 5-HT axons is still rostrocaudal, although many axons travel at some angle to the dorsal surface of the dorsal horn, crossing a larger dorsoventral expanse of the lamina. Additionally, some axons follow a highly curved path within lamina II (Fig. $1 D)$. This trajectory results in several different $5-\mathrm{HT}$ axons crossing over the same area, forming a meshwork of 5-HT axons intertwined in the neuropil of lamina II. 
The immunoreactive 5-HT axons in laminae I and II are marked by numerous varicosities of different sizes which are closely spaced but occur at varying intervals along the strand. The dimensions of 5 - $\mathrm{HT}$ varicosities are marked by a swelling of the axon as well as by the

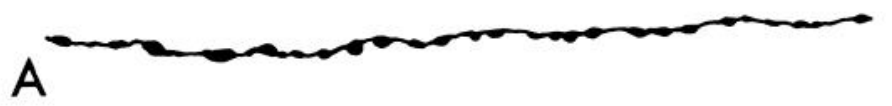

B

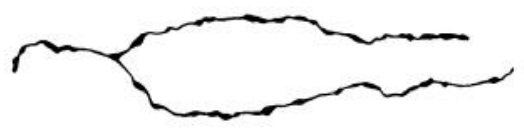

C

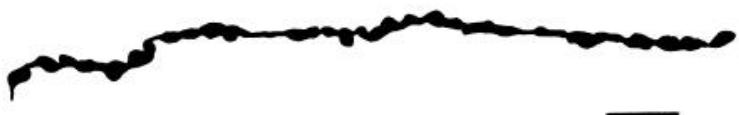

Figure 2. Camera lucida drawings of 5-HT-immunoreactive axons in the sagittal plane in laminae I and II of the dorsal horn. Three different morphological types of axons can be distinguished by the dimensions of the varicosities which occur along the axonal strands. $A$ and $B$ are the most common types found in the superficial laminae, while type $C$ is found infrequently. The axon in $B$ is illustrated at a point where the parent axon has branched to form two similar axonal strands. Scale bar, $10 \mu \mathrm{m}$. noticeably darker immunocytochemical staining of varicose portions of the axon as compared to the intervaricose segment. Based on the size of the varicosities on a single axonal strand, the 5-HT-immunoreactive axons can be divided into at least three different types. All three types are found in both laminae I and II. The most common type of 5-HT axon has both large and small bulbous varicosities intermingled along its length (Fig. $2 A$ ). The varicosities measure 1.2 to $3.5 \mu \mathrm{m}$ in length, with most falling in the range of 2.0 to $3.0 \mu \mathrm{m}$. The width of the varicosities varies from 0.8 to $2.0 \mu \mathrm{m}$, although most measure 1.5 to $2.0 \mu \mathrm{m}$. A second type of 5-HT axon is characterized by small elongated varicosities whose diameter is just slightly larger than that of the intervaricose segment of the axon (Fig. $2 B$ ). A larger bulbous varicosity occasionally is observed along the length of this type of axon (not illustrated). The width of this type of axon's varicosities is relatively uniform and ranges from 0.7 to $1.0 \mu \mathrm{m}$, with most varicosities measuring 0.9 $\mu \mathrm{m}$. The length of the immunoreactive varicosity is variable and ranges from 1.0 to $2.5 \mu \mathrm{m}$, with most varicosities measuring 1.5 to $2.0 \mu \mathrm{m}$ in length. Axons containing these thin boutons en passant are commonly encountered, especially in lamina II. A third type of 5-HT axon is distinguished by numerous large elongated varicosities and a thick intervaricose axon (Fig. $2 \mathrm{C}$ ). These large varicosities occasionally are interspersed with smaller

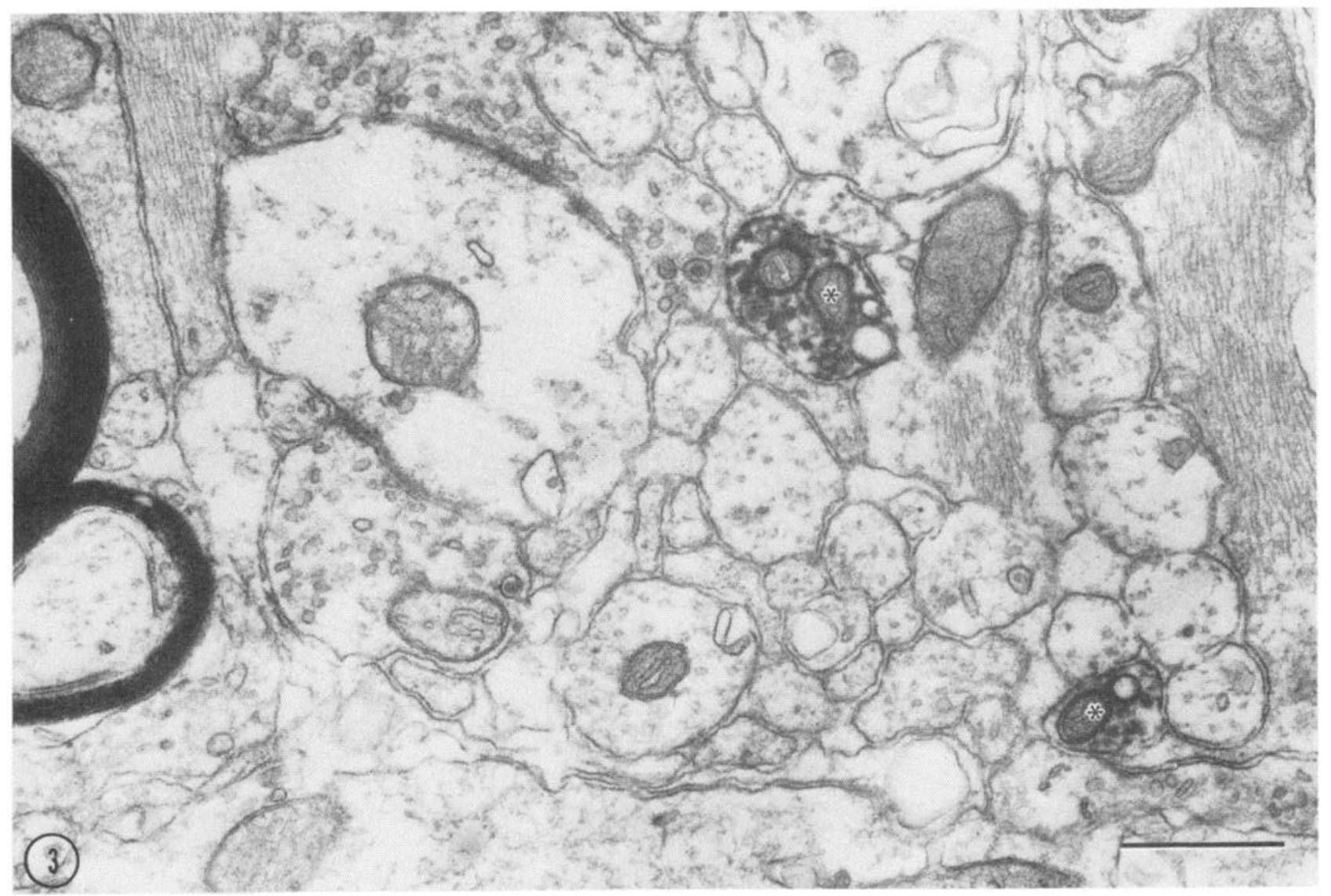

Figure 3. At the ultrastructural level, immunocytochemically labeled profiles are readily distinguished from the normal unlabeled neuropil by the presence of the electron-dense PAP reaction product. In this example, two 5-HT axons (asterisks) are labeled. The 5-HT unmyelinated axons often are found intermingled in groups of similar profiles which are unlabeled. Magnification $\times 42,000$. Scale bar, $0.5 \mu \mathrm{m}$. 
varicosities less than half their size. The dimensions of the varicosities along these axons range from 1.0 to 4.0 $\mu \mathrm{m}$ in length and 1.0 to $3.0 \mu \mathrm{m}$ in width. Most of the large varicosities have a width of at least $2.0 \mu \mathrm{m}$. This type of axon is the least common type encountered in the superficial dorsal horn, while it often is seen in the ventral horn.

\section{Ultrastructural characteristics of 5-HT- immunoreactive axonal endings}

At the ultrastructural level, immunocytochemically labeled 5-HT axonal endings are marked conspicuously by the electron-dense PAP reaction product which coats the outer membrane of the agranular and granular vesicles, the outer mitochondrial membrane, and the dense core of the granular vesicles. The reaction product also is dispersed in the axoplasm. The intervaricose portion of the axon is labeled distinctly with PAP reaction product along the microtubules and axolemma (Figs. 3 and 4). The unmyelinated portion of the 5-HT-immunoreactive axon often is found in bundles of similar profiles less than $0.5 \mu \mathrm{m}$ in diameter, most of which are unlabeled (Fig. 3). These small unmyelinated axons probably represent the terminal arbors of the parent 5-HT axons which descend to the spinal cord from the brain stem. Immunoreactive 5 -HT myelinated axons are not found within the superficial laminae of the dorsal horn.

5-HT-immunoreactive axonal endings are predominantly dome shaped and vary in size from slight vesiclefilled thickenings of the axon just slightly larger than the intervaricose segment (Fig. 4) to large bulbous varicosities (Figs. 5 and 6). The dimensions of the 5-HT-immunoreactive boutons seen at the EM level are comparable to those observed at the LM level (compare Figs. 2, 4, 5,
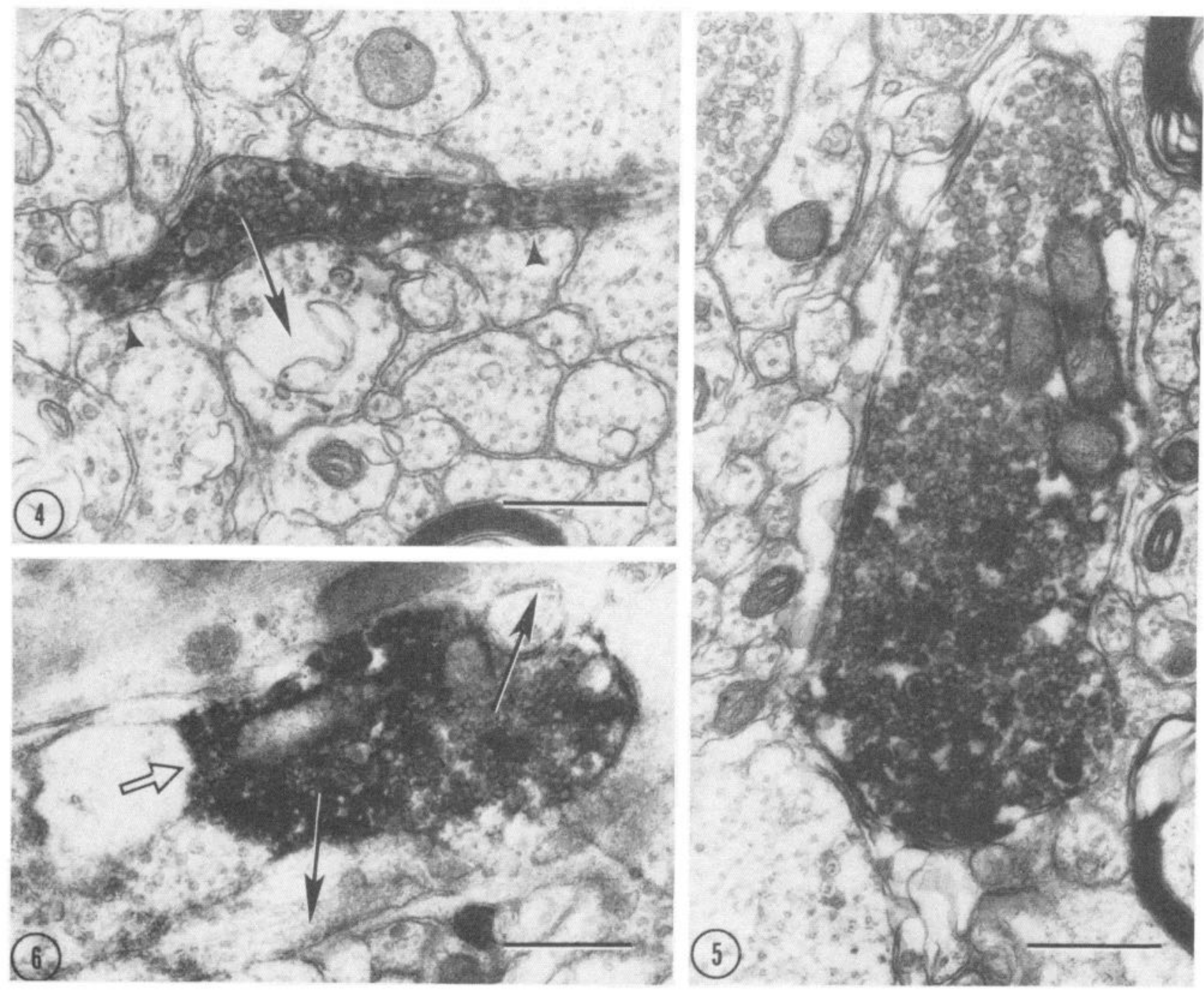

Figure 4. 5-HT-immunoreactive axonal ending synapses (arrow) on a small caliber dendritic shaft. The diameter of the 5-HT ending is just slightly larger than that of the intervaricose portion of the axon (arrowheads) which also contains PAP reaction product. Magnification $\times 40,800$. Scale bar, $0.5 \mu \mathrm{m}$.

Figure 5. Large nonsynaptic 5-HT-immunoreactive varicosity lightly labeled with PAP reaction product around the large dense core vesicles and agranular synaptic vesicles. The dimensions of this varicosity is one of the largest encountered at the ultrastructural level. Magnification $\times 37,200$. Scale bar, $0.5 \mu \mathrm{m}$.

Figure 6. A slightly scalloped 5-HT-immunoreactive central ending has several dendritic profiles impressed into its surface (arrows). Synapses (solid arrows) are found on two of these profiles. Magnification $\times 36,000$. Scale bar, $0.5 \mu \mathrm{m}$. 
and 6). Serotonergic endings characteristically form a single synapse on dendrites or neuronal cell bodies. They do not appear to be involved in axoaxonic synapses, although they often are found adjacent to vesicle-containing profiles. Rarely, the 5-HT endings form large scalloped endings which synapse on several different postsynaptic structures which are impressed into their surface (Fig. 6). Serotonergic axonal varicosities often are observed without a synaptic specialization in a single thin section (Fig. 5). These varicosities are characteristically full of both agranular and large granular vesicles and contain several mitochondria. At times, they are replete with large dense core vesicles. Serial section analysis of these varicosities demonstrates that, in five to six thin sections, most varicosities form a synaptic junction with a nearby neuronal profile. The synaptic junction of 5 -HT axonal endings measured at the ultrastructural level is small $(0.25$ to $0.6 \mu \mathrm{m})$ when compared with the total length of varicosity measured at the light microscopic level (1 to $4 \mu \mathrm{m})$.

Dome-shaped 5-HT-immunoreactive axonal endings can be divided into two major types based on the morphology of their agranular synaptic vesicles. The first type of ending contains a mixture of agranular vesicles which extend from flattened elongated vesicles to round and oval vesicles (Fig. $7 A$ ). The second type is characterized by a relatively homogeneous population of slightly oval agranular vesicles (Fig. $7 B$ ). Both types of endings contain a variable number of large dense core vesicles and are found throughout laminae I and II. The 5-HT endings containing pleomorphic vesicles and those with oval vesicles resemble the D1 and D2 endings, respectively, that were characterized in the medullary dorsal horn in $\left[{ }^{3} \mathrm{H}\right] 5$-HT uptake studies and in 5,6-DHT degeneration studies (Ruda and Gobel, 1980). The same types of endings were shown to originate from the medial brain stem following anterograde transport of $\left[{ }^{3} \mathrm{H}\right]$ leucine (Ruda et al., 1981).

Axodendritic synapses. Serotonergic axodendritic synapses are found throughout laminae I and II. They occur with the greatest frequency in lamina I, decrease in number somewhat in lamina IIa, and are the fewest in lamina IIb. In the superficial neuropil of the dorsal horn, 5 -HT-immunoreactive axonal endings synapse most commonly on small caliber dendritic shafts with a diameter of approximately $1 \mu \mathrm{m}$ (Fig. 7). Large caliber dendritic shafts, which represent the proximal portion of the cell's dendritic tree, also receive synapses from 5-HTimmunoreactive axonal endings, although the frequency of this type of contact is somewhat less than that observed on small caliber dendritic shafts. The smallest caliber dendritic profiles (less than $0.5 \mu \mathrm{m}$ in diameter) receive an occasional 5-HT synaptic contact (Fig. 8). These profiles often are found in bundles of similar profiles, some of which probably represent the thin terminal portion of the dendritic tree or the long necks of dendritic spines. Dendritic spines also receive 5-HT synaptic input, although this type of relationship is the least common site of 5-HT axodendritic synapses (Fig. 9). 5HT-immunoreactive axodendritic contacts are most frequently of the symmetrical type, with a slight accumulation of dense material on the presynaptic and postsynaptic sides of the synaptic junction (Fig. 9). The dense PAP reaction product in the presynaptic 5-HT ending tends to obscure the dense material at the synapse. Asymmetrical 5-HT axodendritic synapses also are found in laminae I and II of the dorsal horn. This type of contact varies from slightly asymmetrical, with a modest
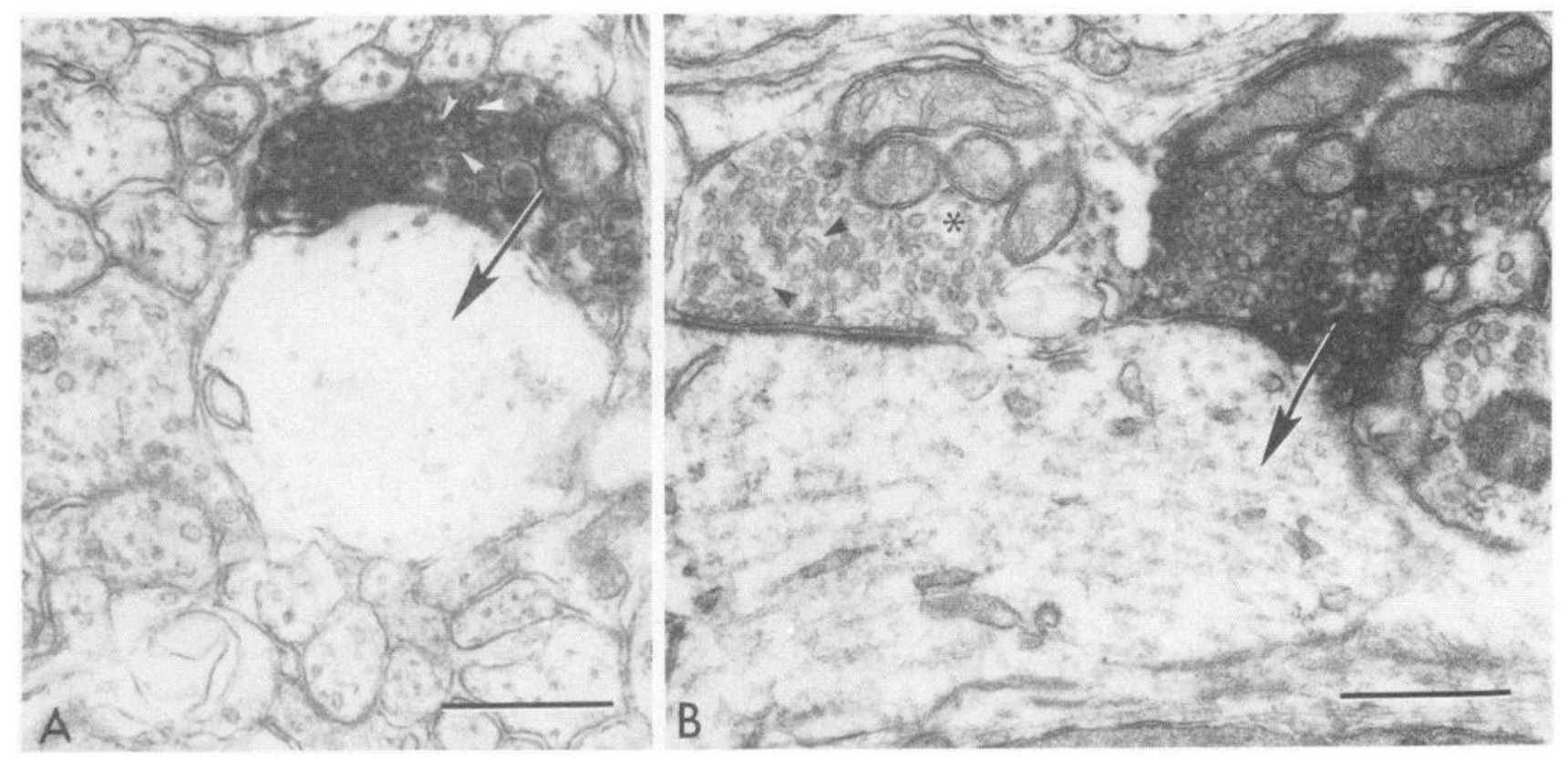

Figure 7. 5-HT-immunoreactive axonal endings which synapse (arrow) on dendrites may contain either a mixture of flattened (white arrowheads) and oval vesicles $(A)$ or a relatively homogeneous population of oval vesicles $(B)$. Unlabeled axonal endings (asterisk) which contain morphologically similar types of vesicles, such as the flattened vesicles illustrated here (black arrowheads; compare $A$ and $B$ ), often synapse on the same neuron as endings immunoreactive for 5 -HT. Magnification $\times 38,400$. Scale bar, $0.5 \mu \mathrm{m}$. 

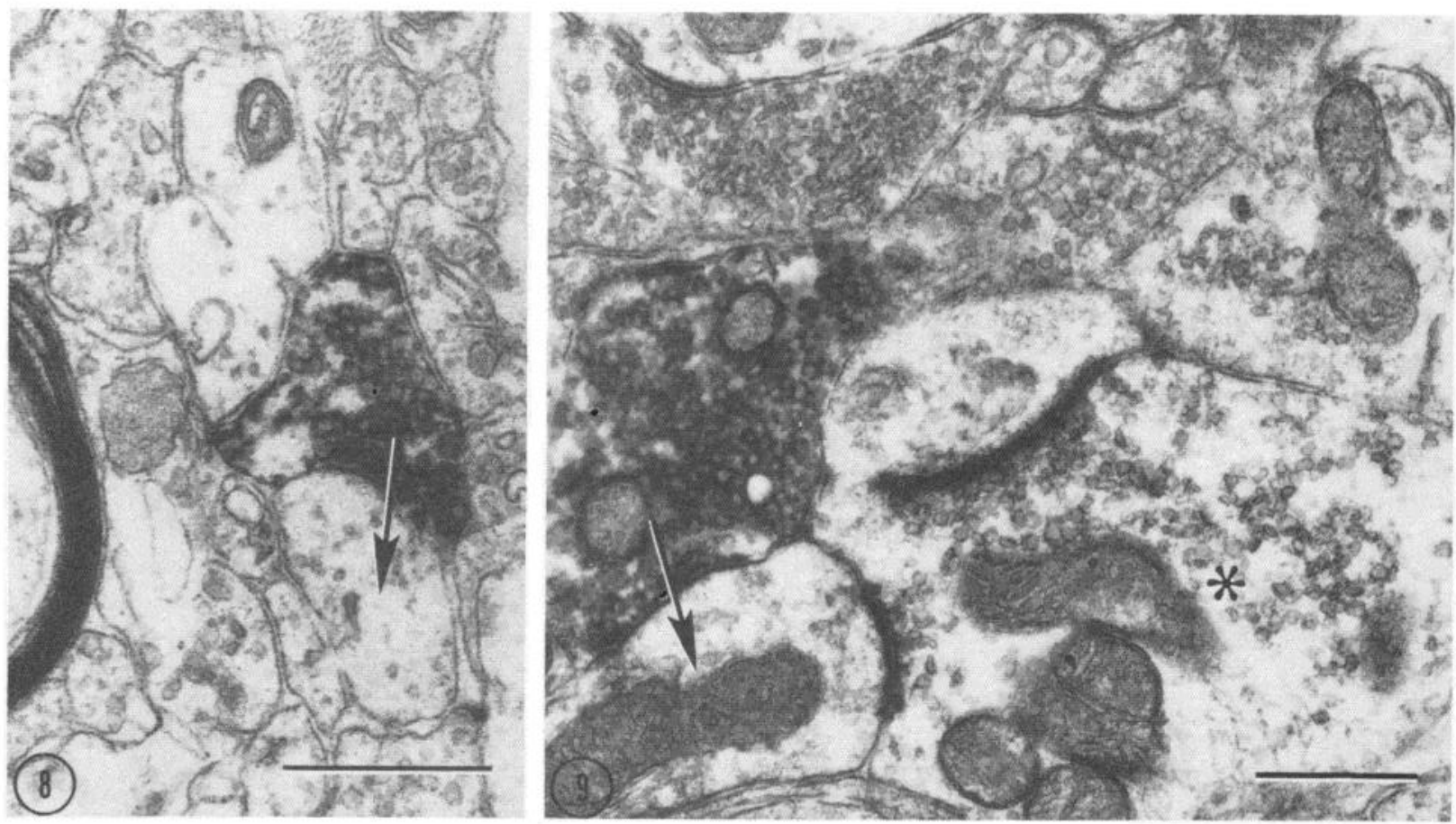

Figure 8. The smallest caliber dendritic profiles of dorsal horn neurons also receive synapses from 5-HT axonal endings. In this particular example, the synapse is slightly asymmetrical (arrow). Magnification $\times 46,500$. Scale bar, $0.5 \mu \mathrm{m}$.

Figure 9. Dendritic spines occasionally receive 5-HT input. The same dendritic spine which receives a symmetrical 5-HT synapse (arrow) is also postsynaptic to an unlabeled central ending (asterisk). Magnification $\times 36,000$. Scale bar, $0.5 \mu \mathrm{m}$.

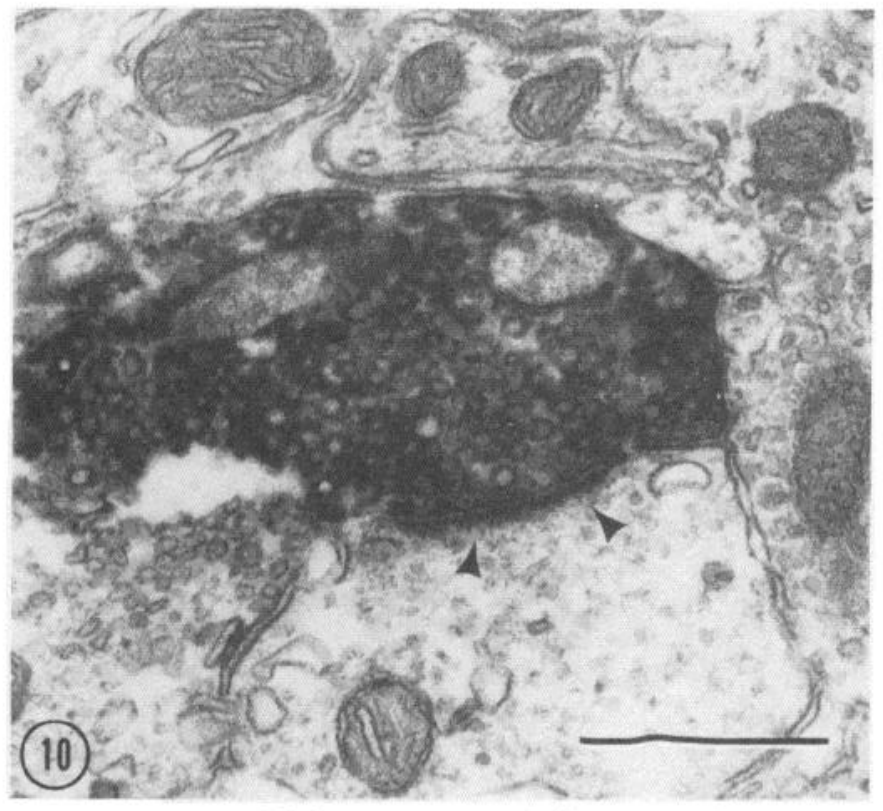

Figure 10. In addition to symmetrical synaptic junctions, 5HT-immunoreactive axonal endings occasionally form asymmetrical contacts with a prominent subsynaptic density (arrowheads). Magnification $\times 49,600$. Scale bar, $0.5 \mu \mathrm{m}$.

accumulation of dense material on the postsynaptic side (Fig. 8), to a prominent asymmetrical synapse, with a heavy accumulation of dense material (Fig. 10). The prominent asymmetrical synapse is the least common type.

The dendrites in laminae I and II of the dorsal horn which receive 5-HT input may originate from at least three different morphological types of neurons. The most common type of dendrite is characterized by a light to moderate cytoplasmic matrix and is found in both laminae I and II (Fig. 11A). A second type is distinguished by a denser cytoplasmic matrix (Fig. 11B) and is located primarily in lamina II, especially lamina IIb. The third type of dendrite is unique in that flattened agranular synaptic vesicles are present in its shaft (Fig. 11C). This type of dendrite has a light cytoplasmic matrix which typically appears disrupted and contains large cavities (Fig. 11, $C$ and $D$ ). It is usually found in lamina I.

Axosomatic synapses. Symmetrical 5-HT axosomatic synapses (Fig. 12) are found in laminae I and II. Both 5HT axonal endings with pleomorphic vesicles and those with oval vesicles form axosomatic synapses. In lamina I, neuronal cell bodies sometimes are contacted by several 5-HT-immunoreactive axonal endings. Since each lamina of the dorsal horn contains different morphological and functional types of neurons (Bennett et al., 1979, 1980, 1981; Light et al., 1979), the observation of axosomatic synapses in each lamina suggests that 5 - $\mathrm{HT}$ input is received by more than one type of neuron.

\section{Discussion}

erotonin axons can be localized immunocytochemically to both laminae I and II of the spinal cord of the cat. Their decidedly rostrocaudal orientation with numerous varicosities suggests that a single axon makes multiple contacts with dorsal horn neurons whose dendrites are oriented in the rostrocaudal direction. Studies of horseradish peroxidase-filled primary afferent axons demonstrate that, in the superficial laminae, some primary axons distribute as single long strands with many varicosities and few branches (Gobel et al., 1981b). Some of these primary axons may represent $\mathrm{A} \delta$ or $\mathrm{C}$ nociceptors. The similar morphology and orientation of the 5- 

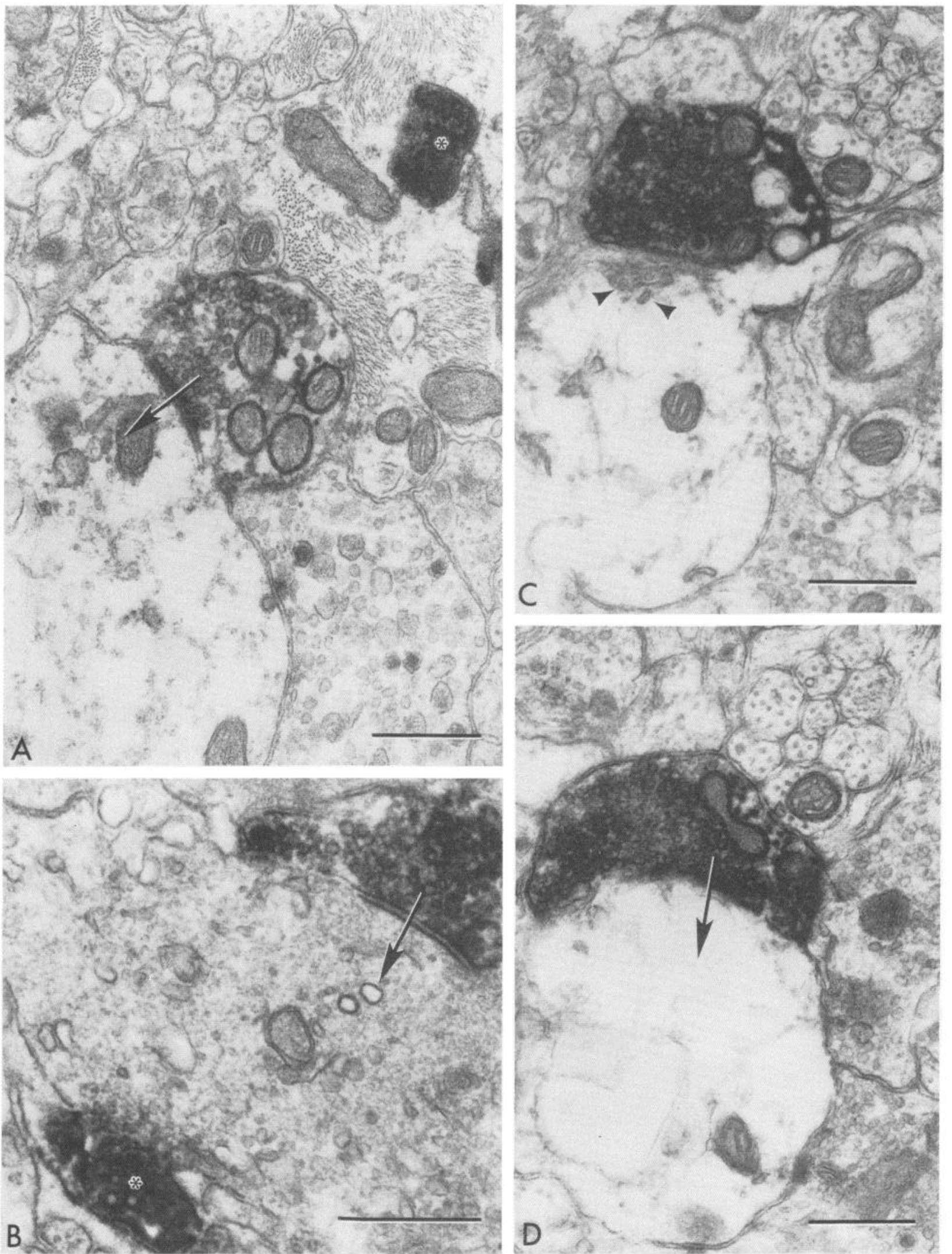

Figure 11. Three different morphological types of dendrites receive 5-HT input. $A$, The most common type of dendrite which receives synapses (arrow) from 5-HT axonal endings has a light cytoplasmic matrix. This particular 5-HT ending is partially sheathed by a glial cell which exhibits endogenous peroxidase activity in a lysosome (asterisk). Magnification $\times 37,800$. $B$, The second type of dendrite is distinguished by a denser cytoplasmic matrix which has a darker appearance. In this example, the same portion of a dendrite which receives a synapse (arrow) from the labeled 5-HT ending in the upper right of the figure was observed in serial sections to receive a second 5-HT synapse from the preterminal 5-HT varicosity in the lower left (asterisk). Magnification $\times 50,400$. $C$, The third type of dendrite to receive 5 -HT input is distinguished by the presence of flattened agranular vesicles (arrowheads) at focal sites within the dendritic shaft. Magnification $\times 37,200 . D$, In serial section analysis, the vesicle-containing dendrite in $C$ receives a synapse (arrow) from the labeled 5-HT ending at a site some distance from the focal accumulation of flattened vesicles. Magnification $\times 37,200$. Scale bars, $0.5 \mu \mathrm{m}$. 


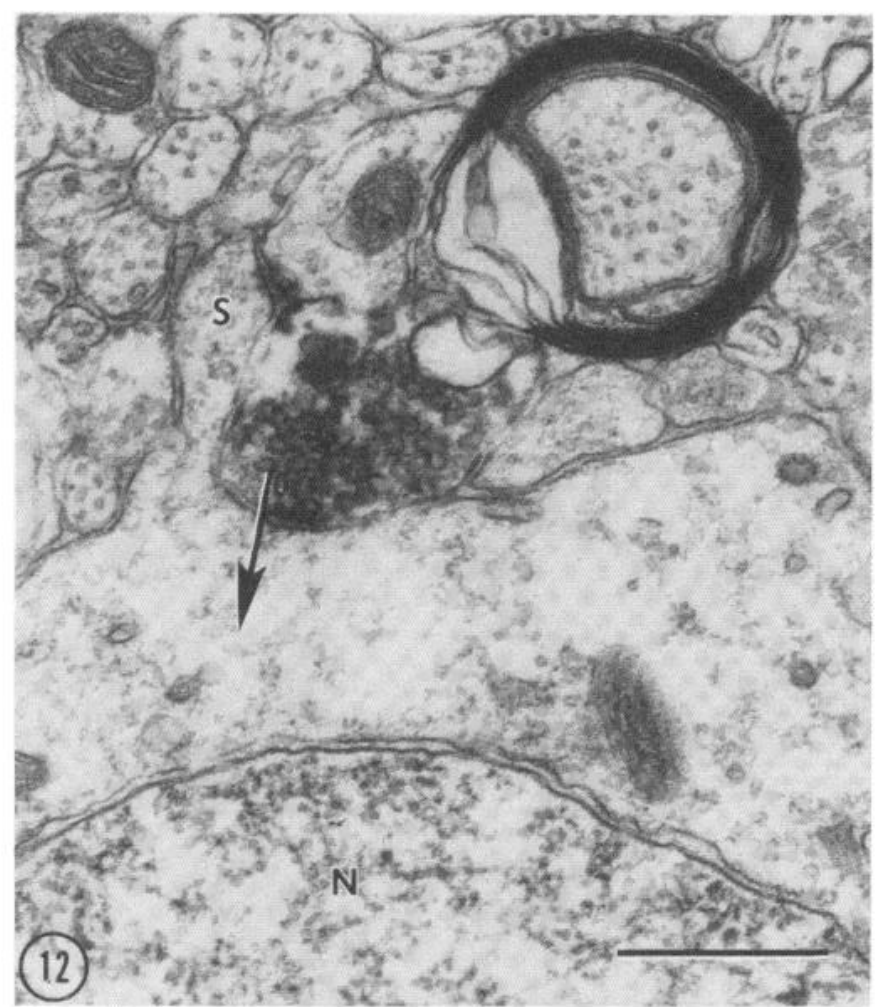

Figure 12. 5-HT-immunoreactive axosomatic synapses occur in both laminae I and II. This 5-HT axonal ending in lamina I contains pleomorphic vesicles and forms a symmetrical synapse (arrow) on a neuronal cell body adjacent to a small somatic spine $(S)$. Part of the cell's nucleus $(N)$ also is present. Magnification $\times 42,000$. Scale bar, $0.5 \mu \mathrm{m}$.

HT axons allows them to follow the distribution of the nociceptive afferents closely. Since 5-HT axoaxonic synapses are not found in the superficial dorsal horn, the parallel orientation of 5-HT and primary afferent axons in lamina I demonstrates that 5-HT input is situated strategically to influence primary afferent input soon after it is transmitted to dorsal horn neurons. The rostrocaudal orientation of 5-HT may explain, in part, the changes in the receptive fields of dorsal horn neurons after electrical stimulation of the central gray or systemic administration of morphine. In each case, the receptive fields of wide dynamic range neurons shrank to small areas, responsive only to gentle mechanical stimulation (Hayes et al., 1979). Descending 5-HT axons therefore may play a role in the modulation of receptive field size.

Ultrastructural observations of 5-HT-immunoreactive axonal endings localize the monoamine to endings containing either pleomorphic synaptic vesicles or oval synaptic vesicles. The presence of two morphologically distinct populations of vesicles in 5 - $\mathrm{HT}$ endings implies that 5 -HT endings in the superficial dorsal horn originate from disparate neuronal cell types which may be located in different 5-HT nuclear groups. It is not known whether the nonuniform morphology in synaptic vesicles also implies a variety in function. Although the morphological heterogeneity of vesicles in 5-HT endings also has been observed in other sites in the neuraxis (Chan-Palay, 1975, 1978), there does not appear to be a distinctive morphological feature of 5-HT endings which distinguishes them from axons containing other neurotransmitters. In the dorsal horn, 5-HT axonal endings resemble those which contain norepinephrine (Ruda et al., 1979), enkephalin (Aronin et al., 1981; M. A. Ruda, unpublished observations), and substance P (Barber et al., 1979; M. A. Ruda, unpublished observations). Norepinephrine-containing axonal endings with pleomorphic vesicles and those with oval vesicles are found in about the same proportion as similar 5-HT axonal endings, although the total number of norepinephrine endings in the dorsal horn appears to be less than that of 5-HT endings. For the peptides enkephalin and substance $\mathrm{P}$ in the superficial dorsal horn, axonal endings containing round or oval vesicles are the most common type. We often have observed axonal endings with morphologically identical synaptic vesicles synapsing on the same neuronal profile where only one ending is labeled immunocytochemically (Fig. $7 B$ ). The adjacent morphologically identical but unlabeled ending must contain a different neurotransmitter. These observations emphasize that the definitive determination of the presence of a neurotransmitter in an axonal ending cannot be made based on morphological criteria alone and requires some type of cytochemical label.

Recently, considerable evidence has accumulated for the coexistence of a biogenic amine and a neuropeptide in the same neuronal cell body (see Hökfelt et al., 1980, for review). In the brain stem raphe cell groups, 5-HT has been shown to coexist with substance $\mathrm{P}$ (Chan-Palay et al., 1978; Hökfelt et al., 1978), enkephalin (Glazer et al., 1981), and thyrotropin-releasing hormone (TRH) (Johansson et al., 1981). In an elegant series of double labeling experiments, substance P-containing neurons (Bowker et al., 1981b) and enkephalin-containing neurons (Hökfelt et al., 1979; Bowker et al., 1981b) in the serotonin-rich raphe cell groups were demonstrated to send their axons to the spinal cord. Most recently, 5-HT and substance $\mathrm{P}$ were localized to the same axonal endings in the spinal cord (Pelletier et al., 1981). Based on similar ultrastructural morphology of some 5-HT, norepinephrine, enkephalin, and substance $P$ endings in the dorsal horn, it is possible that some endings contain both an amine and a peptide. However, this criteria cannot be taken as a valid indicator of coexistence since there is considerable evidence for uniquely aminergic or peptidergic endings. Further experiments will be needed to determine the relative frequency of 5-HT input coexistent with a neuropeptide in each lamina of the spinal cord. The differential laminar staining patterns of enkephalin and substance $\mathrm{P}$, when compared with that of 5-HT (M. A. Ruda, unpublished observations), clearly show that some laminae of the dorsal horn which contain high levels of 5-HT immunoreactivity contain little, if any, enkephalin or substance $\mathrm{P}$ immunoreactivity, suggesting that some 5-HT axons in the dorsal horn contain neither enkephalin nor substance P. Based on immunocytochemical staining and radioimmunoassay for substance $\mathrm{P}$ and TRH following application of the 5-HT neurotoxins, 5,6- and 5,7-DHT, it appears that axons containing both the amine and peptide are largely confined to the ventral horn (Gilbert et al., 1982). In the dorsal horn, some descending 5-HT axons may contain substance $\mathbf{P}$ since radioimmunoassay detected a small drop in substance $\mathrm{P}$ levels after treatment with the 
neurotoxin 5,6-DHT (Gilbert et al., 1982). A slight amount of substance $\mathbf{P}$ staining remains in the dorsal horn after rhizotomy to remove substance $\mathrm{P}$-containing primary afferent input (Hökfelt et al., 1975; Barber et al., 1979; Jessell et al., 1979), but this may be due, in part, to the staining of the dendritic and axonal arbors of intrinsic substance $\mathrm{P}$ neurons (Hunt et al., 1981).

Although there is evidence for enkephalin-containing cell bodies in the brain stem which send their axons to the spinal cord (Hökfelt et al., 1979; Bowker et al., 1981b), the contribution of descending enkephalin, or for that matter, coexistent 5-HT and enkephalin, axons to the neural circuitry of the dorsal horn is not clearly defined. Undoubtedly, most of the enkephalin staining in the dorsal horn can be attributed to intrinsic enkephalinergic dorsal horn neurons which are located in laminae I, II, III, and V (Glazer and Basbaum, 1981; Hunt et al., 1981; Bennett et al., 1982). Immunocytochemical analysis of enkephalin following transection of the spinal cord demonstrates no detectable change in the staining pattern (Seybold and Elde, 1980; Naftchi et al., 1981). These dats suggest that descending enkephalin axons, if present in the dorsal horn, reflect only a small component of the total amount of enkephalin present. Radioimmunoassay of enkephalin levels after treatment with the 5-HT neurotoxin 5,6-DHT shows an increase of enkephalin rather than the decrease that would be expected if 5-HT and enkephalin coexist in the same axon (Gilbert et al., 1982). It is possible that the increase in enkephalin levels is due to transneuronal effects. Thus, despite the morphological similarity between immunocytochemically labeled 5-HT and enkephalin axonal endings, it is unlikely that most 5-HT endings in the dorsal horn also contain enkephalin.

Serotonin is found in the same laminae with similar density in both the medullary and spinal dorsal horns. Previous studies using the uptake of $\left[{ }^{3} \mathrm{H}\right] 5$-HT to mark 5-HT axonal endings autoradiographically have identified several different morphological types of 5-HT endings in the medullary dorsal horn (Ruda and Gobel, 1980). Our immunocytochemical observations in the spinal dorsal horn are in general agreement with those made in the medulla. In the superficial laminae of both the medullary and spinal dorsal horns, most 5-HT axonal endings are dome shaped and synapse primarily on dendrites and occasionally on neuronal cell bodies. The vesicle complement of the $5-\mathrm{HT}$ endings identified in this study resemble that of the D1 and D2 endings described in the medulla. The D1 type ending is characterized by the presence of flattened agranular vesicles, while the D2 type ending contains mainly oval agranular vesicles. However, using the immunocytochemical technique in the spinal dorsal horn, 5-HT endings of the D1 type tend to have a greater mixture of vesicle shape, ranging from flattened vesicles to small oval vesicles. Dome-shaped endings containing almost exclusively highly flattened vesicles (Ruda and Gobel, 1980) are not labeled immunocytochemically. In addition, immunocytochemically labeled D2 type endings tend, at times, to contain round vesicles in addition to oval vesicles. These slight morphological differences may be due to several factors. The concentration of aldehyde fixatives used in each study differed significantly, potentially altering vesicle shape (Walberg, 1966). Since only the immunocytochemical technique requires the development of the reaction product in diaminobenzidine, incubation of the tissue in this medium prior to osmication also may alter the morphology of the vesicles by chemical changes produced in the labeled ending during the development of the PAP reaction product. Additionally, the PAP reaction product coats the vesicles and may obscure their true shape. Lastly, the subtle differences in vesicle morphology in some endings in the medullary and spinal dorsal horns may reflect a different "parent" cell origin in the brain stem serotonergic cell groups. In the rat, the cervical spinal cord, but not the lumbar spinal cord, receives afferents from serotonin neurons in the midbrain reticular formation and central gray (Bowker et al., 1981a). Although some serotonergic cell groups project to several levels of the spinal cord (Bowker et al., 1981a), it is unclear as to whether the same 5-H'T neuron issues collaterals to all levels of the spinal cord.

Large central endings which form synapses with several different dendritic profiles were termed $S$ type endings in the $\left[{ }^{3} \mathrm{H}\right] 5-\mathrm{H}$ T uptake studies in the medullary dorsal horn (Ruda and Gobel, 1980). At the light microscopic level, large, dark immunoreactive varicosities are found in the superficial laminae of the spinal dorsal horn with dimensions comparable to those of the $S$ type endings. However, at the ultrastructural level in the spinal dorsal horn, $S$ type endings are rarely labeled immunocytochemically. Although the $\mathrm{S}$ type endings were likewise rare in the medullary dorsal horn, their occurrence was somewhat greater than that observed at spinal levels. This dissimilarity in the frequency of labeled 5-HT S type endings may reflect differences in the techniques used to label 5-HT endings in the medulla and spinal cord. Some $S$ type enings may take up $\left[{ }^{3} \mathrm{H}\right] 5-\mathrm{HT}$ nonspecifically or are not recognized by our antiserum to $5-\mathrm{HT}$, perhaps because of the slight amount of 5-HT naturally present in the ending or because the 5-HT is in a precursor or breakdown form. Large $\mathrm{S}$ type endings have been observed in the cerebellum following the uptake of $\left[{ }^{3} \mathrm{H}\right]$ $5-\mathrm{HT}$, indicating that the large scalloped central ending is a true morphological type of 5-HT ending (Chan-Palay, 1975). However, this type of 5-HT ending has not been described in other parts of the nervous system (Descarries et al., 1975; Calas et al., 1976; Leger and Descarries, 1978), suggesting that the $5-\mathrm{HT}$ neurons whose axons form the $S$ type ending have a limited distribution.

Our analysis of 5-HT in the superficial dorsal horn indicates that 5-HT acts at multiple sites and may modulate the response of at least three different neuronal cell types in the dorsal horn. Since 5-HT axonal endings do not appear to synapse directly on primary afferent axons in the cat dorsal horn, their main site of action is on the intrinsic dorsal horn neurons. A key issue is to determine which dorsal horn neurons receive 5-HT input. 5-HT axosomatic synapses are found on neurons in laminae I and II. Since each lamina contains different neuronal cell types, the presence of 5-HT synapses on the somata of neurons in these different laminae provides strong evidence for multiple sites of action of 5-HT in the dorsal horn. Lamina I contains long distance projection neurons (Carstens and Trevino, 1978; Brown et al., 1980) in addition to neurons with a local axonal arbor (Bennett et al., 1981) which may function as interneurons. 5-HT may 
modulate the response of thalamic projection neurons to noxious stimulation either directly or through synapses on interneurons in the dorsal horn. The dense plexus of 5 -HT axons in lamina $I$ is situated strategically to modulate the response of the projection neurons directly. Physiological studies suggest that there may be a direct 5-HT input onto lamina I projection neurons (Yezierski et al., 1982; Jordan et al., 1979). Anatomical demonstration of direct 5-HT input onto lamina I projection neurons would provide an important observation of the site of action of $5-\mathrm{HT}$.

Lamina II of the dorsal horn is composed almost entirely of interneurons. Since the outer part of lamina II contains a dense plexus of 5-HT axons, it is likely that 5 -HT axons synapse on the dendrites of lamina II interneurons as well as an occasional synapse on the cell body. The two major types of interneurons in lamina II include stalked cells and islet cells (Gobel, 1978), each of which may receive 5-HT synapses (Hoffert et al., 1982). Stalked cells are likely candidates to receive 5-HT synapses, especially since their dendrites are devoid of synaptic vesicles (Gobel et al., 1980) and, as such, match those in this study. Islet cells contain round and oval synaptic vesicles inside of their dendritic shafts and spines and are proposed inhibitory interneurons (Gobel et al., 1980). Since no 5-HT synapses are observed on profiles containing round and oval vesicles, 5 -HT input to islet cells, if present, must occur on parts of the dendritic tree without vesicles. This would place 5 -HT input at sites between the dendrodendritic and dendroaxonic synaptic transfer of islet cell information in lamina II. The neuropil of the superficial dorsal horn also contains dendrites of neurons whose cell body lies in deeper lamina of the dorsal horn, such as laminae IV and V (Szentagothai, 1964). It is likely that the dendrites of these deeper neurons receive $5-\mathrm{HT}$ input in the superficial dorsal horn (Hoffert et al., 1982).

Based on the presence of 5-HT synapses on the cell bodies of neurons in laminae I and II and the morphological differences that one observes in the dendrites which are postsynaptic to 5-HT-immunoreactive axonal endings, it is probable that 5 -HT acts at multiple sites in the superficial laminae of the dorsal horn.

\section{References}

Akil, H., and D. J. Mayer (1972) Antagonism of stimulationproduced analgesia by p-CPA, a serotonin synthesis inhibitor. Brain Res. 44: 692-697.

Aronin, N., M. DiFiglia, A. S. Liotta, and J. B. Martin (1981) Ultrastructural localization and biochemical features of immunoreactive Leu-enkephalin in monkey dorsal horn. J. Neurosci. 1: 561-577.

Barber, R., J. E. Vaughn, J. R. Slemmon, P. M. Salvaterra, E. Roberts, and S. E. Leeman (1979) The origin, distribution and synaptic relationships of substance $P$ axons in rat spinal cord. J. Comp. Neurol. 184: 331-351.

Belcher, G., R. W. Ryall, and R. Schaffner (1978) The differential effects of 5-hydroxytryptamine, noradrenaline, and raphe stimulation on nociceptive and non-nociceptive dorsal horn interneurons in the cat. Brain Res. 151: 307-321.

Bennett, G. J., H. Hayashi, M. Abdelmoumene, and R. Dubner (1979) Physiological properties of stalked cells of the substantia gelatinosa intracellularly stained with horseradish peroxidase. Brain Res. 164: 285-189.

Bennett, G. J., M. Abdelmoumene, H. Hayashi, and R. Dubner (1980) Physiology and morphology of substantia gelatinosa neurons intracellularly stained with horseradish peroxidase. J. Comp. Neurol. 194: 809-827.

Bennett, G. J., M. Abdelmoumene, H. Hayashi, M. J. Hoffert, and R. Dubner (1981) Spinal cord layer I neurons with axon collaterals that generate local arbors. Brain Res. 209: 421426.

Bennett, G. J., M. A. Ruda, S. Gobel, and R. Dubner (1982) Enkephalin immunoreactive stalked cells, and lamina IIb islet cells in cat substantia gelatinosa. Brain Res. 240: 162-166.

Bowker, R. M., K. N. Westlund, and J. D. Coulter (1981a) Origins of serotonergic projections to the spinal cord in rat: An immunocytochemical-retrograde transport study. Brain Res. 226: 187-199.

Bowker, R. M., H. W. M. Steinbusch, and J. D. Coulter (1981b) Serotonergic and peptidergic projections to the spinal cord demonstrated by a combined retrograde HRP histochemical and immunocytochemical staining method. Brain Res. 211: 412-417.

Brown, A. G., R. E. W. Fyffe, R. Nobel, P. K. Rose, and P. J. Snow (1980) The density distribution and topographical organization of spinocervical tract neurones in the cat. J. Physiol. (Lond.) 300: 409-428.

Calas, A., M. J. Besson, C. Gauchy, G. Alonso, J. Glowinski, A. Cheramy (1976) Radioautographc study of in vivo incorporation of $\left[{ }^{3} \mathrm{H}\right]$ manoamines in the cat caudate: identification of serotoninergic fibers. Brain Res. 118: 1-13.

Carstens, E., and D. J. Trevino (1978) Laminar origins of spinothalamic projections in the cat as determined by the retrograde transport of horseradish peroxidase. J. Comp. Neurol. 182: 151-166.

Chan-Palay, V. (1975) Fine structure of labelled axons in the cerebellar cortex and nuclei of rodents and primates after intraventricular infusions with tritiated serotonin. Ant. Embryol. (Berl.) 148: 235-265.

Chan-Palay, V. (1978) The paratrigeminal nucleus. II. Identification and inter-relations of catecholamine axons, indoleamine axons and substance $\mathrm{P}$ immunoreactive cells in the neuropil. J. Neurocytol. 7: 419-442.

Chan-Palay, V., G. Jonsson, and S. L. Palay (1978) Serotonin and substance $P$ coexist in neurons of the rat's central nervous system. Proc. Natl. Acad. Sci. U. S. A. 75: 1582-1586.

Dahlström, A., and K. Fuxe (1964) Evidence for the existence of monoamine-containing neurons in the central nervous system. I. Demonstration of monoamines in the cell bodies of brain stem neurons. Acta Physiol. Scand. Suppl. 232 62: 155.

Dahlström, A., and K. Fuxe (1965) Evidence for the existence of monoamine neurons in the central nervous system. II. Experimentally induced changes in the intraneuronal amine levels of bulbospinal neuron systems. Acta Physiol. Scand. Suppl. 247 64: 1-36.

Descarries, L., A. Beuadet, and K. C. Watkins (1975) Serotonin nerve terminals in adult rat neocortex. Brain Res. 100: 563-588.

Dubner, R., and G. J. Bennett (1982) Spinal and trigeminal mechanisms of nociception. Annu. Rev. Neurosci., in press.

Fuxe, K. (1965) Evidence for the existence of monoamine neurons in the central nervous system. IV. Distribution of monoamine nerve terminals in the central nervous system. Acta Physiol. Scand. Suppl. 247 64: 37-85.

Gilbert, R. F. T., P. C. Emson, S. P. Hunt, G. W. Bennett, C. A. Marsden, B. E. B. Sandberg, H. W. M. Steinbusch, and A. A. J. Verhofstad (1982) The effects of monoamine neurotoxins on peptides in the rat spinal cord. Neuroscience 7:69-87.

Glazer, E. J., and A. I. Basbaum (1981) Immunohistochemical localization of leucine-enkephalin in the spinal cord of the cat: Enkephalin-containing marginal neurons and pain modulation. J. Comp. Neurol. 196: 377-389. 
Glazer, E. J., H. W. M. Steinbusch, A. A. J. Verhofstad, and A. I. Basbaum (1981) Serotonergic neurons in nucleus raphe dorsalis and paragigantocellularis of the cat contain enkephalin. J. Physiol. (Paris) 77: 241-245.

Gobel, S. (1978) Golgi studies of the neurons in layer II of the dorsal horn of the medulla (trigeminal nucleus caudalis). J. Comp. Neurol. 180: 395-413.

Gobel, S., W. M. Falls, G. J. Bennett, M. Abdelmoumene, H. Hayashi, and E. Humphrey (1980) An EM analysis of the synaptic connections of horseradish peroxidase-filled stalked cells and islet cells in the substantia gelatinosa of the adult cat spinal cord. J. Comp. Neurol. 194: 781-808.

Gobel, S., S. Hockfield, and M. A. Ruda (1981a) An anatomical analysis of the similarities between medullary and spinal dorsal horns. In Oral-Facial Sensory and Motor Functions, Y. Kawamura and R. Dubner, eds., pp. 211-223, Quintessence, Tokyo.

Gobel, S., W. M. Falls, and E. Humphrey (1981b) Morphology and synaptic connections of ultrafine primary axons in lamina I of the spinal dorsal horn: Candidates for the terminal axonal arbors of primary neurons with unmyelinated (C) axons. J. Neurosci. 1: 1163-1179.

Griersmith, B. T., and A. W. Duggan (1980) Prolonged depression of spinal transmission of nociceptive information by $5 \mathrm{H} T$ administered in the substantia gelatinosa: Antagonism by methysergide. Brain Res. 187: 231-236.

Hayes, R. L., D. D. Price, M. A. Ruda, and R. Dubner (1979) Suppression of nociceptive responses in the primate by electrical stimulation of the brain or morphine administration: Behavioral and electrophysiological comparisons. Brain Res. 167: 417-421.

Hoffert, M. J., V. Miletic, M. A. Ruda, and R. Dubner (1982) Immunocytochemical identification of serotonergic contracts on characterized neurons in cat spinal dorsal horn. Anat. Rec., in press.

Hökfelt, T., J. O. Kellerth, G. Nilsson, and B. Pernow (1975) Experimental immunohistochemical studies on the localization and distribution of substance $P$ in cat primary sensory neurons. Brain Res. 100: 235-252.

Hökfelt, T., A. Ljungdahl, H. Steinbusch, A. Verhofstad, G. Nilsson, E. Brodin, B. Pernow, and M. Goldstein (1978) Immunohistochemical evidence of substance P-like immunoreactivity in some $5 \mathrm{HT}$ containing neurons in the rat central nervous system. Neuroscience 3: 517-538.

Hökfelt, T., L. Terenius, H. G. J. M. Kuypers, and O. Dann (1979) Evidence for enkephalin immunoreactive neurons in the medulla oblongata projecting to the spinal cord. Neurosci. Lett. 14: 55-60.

Hökfelt, T., J. Lundberg, M. Schultzberg, O. Johansson, A. Ljungdahl, and J. Rehfeld (1980) Coexistence of peptides and putative transmitters in neurons. In Neural Peptides and Neuronal Communication, E. Costa and M. Trabucchi, eds., pp. 1-23, Raven Press, New York.

Hunt, S. P., J. S. Kelly, P. C. Emson, J. R. Kimmel, R. J. Miller, and J. Y. Wu (1981) An immunohistochemical study of neuronal populations containing neuropeptides or gammaaminobutyrate within the superficial layers of the rat dorsal horn. Neuroscience 6: 1883-1898.

Jessell, T., A. Tsunov, I. Kanazawa, and M. Otsuka (1979) Substance P: Depletion in the dorsal horn of rat spinal cord after section of the peripheral processes of primary sensory neurons. Brain Res. 168: 247-259.

Johansson, O., 'T'. Hökfelt, B. Pernow, S. L. Jeffcoate, N. White, H. W. M. Steinbusch, A. A. J. Verhofstad, P. C. Emson, and E. Spindel (1981) Immunohistochemical support for three putative transmitters in one neuron: Coexistence of 5-hydroxytryptamine, substance P- and thyrotropin releasing hormone-like immunoreactivity in medullary neurons projecting to the spinal cord. Neuroscience 6: 1857-1881.
Jordan, L. M., D. R. Kenshalo, Jr., R. F. Martin, L. H. Haber, and W. D. Willis (1979) Two populations of spinothalamic tract neurons with opposite responses to 5-hydroxytryptamine. Brain Res. 164: 342-346.

Leger, L., and L. Descarries (1978) Serotonin nerve terminals in the locus coeruleus of adult rat: A radioautographic study. Brain Res. 145: 1-13.

Light, A. R., D. L. Trevino, and E. R. Perl (1979) Morphological features of functionally defined neurons in the marginal zone and substantia gelatinosa of the spinal dorsal horn. J. Comp. Neurol. 186: 151-171.

Messing, R. B., and L. D. Lytle (1977) Serotonin-containing neurons: Their possible role in pain and analgesia. Pain 4: 121.

Naftchi, N. E., S. J. Abrahams, H. M. St. Paul, and L. L. Vacca (1981) Substance $\mathrm{P}$ and leucine enkephalin changes after chordotomy and morphine treatment. Peptides Suppl. 12 : 61-70.

Pelletier, G., H. W. M. Steinbusch, and A. A. J. Verhofstad (1981) Immunoreactive substance $P$ and serotonin present in the same dense-core vesicles. Nature 293: 71-72.

Randic, M., and H. H. Yu (1976) Effects of 5-hydroxytryptamine and bradykinin in cat dorsal horn neurones activated by noxious stimuli. Brain Res. 111: 197-203.

Ruda, M. A., and S. Gobel (1980) Ultrastructural characterization of axonal endings in the substantia gelatinosa which take up $\left[{ }^{3} \mathrm{H}\right]$ serotonin. Brain Res. 184: 57-83.

Ruda, M. A., B. Allen, and S. Gobel (1979) Ultrastructura] characterization of noradrenergic axonal endings in layers I and II of the dorsal horn of the medulla. Soc. Neurosci. Abstr. 5: 712 .

Ruda, M. A., B. Allen, and S. Gobel (1981) Ultrasturctural analysis of medial brain stem afferents to the superficial dorsal horn. Brain Res. 205: 175-180.

Seybold, V., and B. Elde (1980) Immunohistochemical studies of peptidergic neurons in the dorsal horn of the spinal cord. J. Histochem. Cytochem. 28: 367-370.

Steinbusch, H. W. M. (1981) Distribution of serotonin-immunoreactivity in the central nervous system of the rat. Cell bodies and terminals. Neuroscience 6 : 557-618.

Steinbusch, H. W. M., A. A. J. Verhofstad, and H. W. J. Joastern (1978) Localization of serotonin in the central nervous system by immunohistochemistry. Neuroscience 3: 811819.

Steinbusch, H. W. M., A. A. J. Verhofstad, and H. W. J. Joasten (1982) Antibodies to serotonin for neuroimmunocytochemical studies on the central nervous system. Methodological aspects and applications. In IBRO Handbook Series. Methods in the Neurosciences: Neuroimmunocytochemistry, A. C. Cuello, ed., John Wiley and Sons, New York, in press.

Sternberger, L. A. (1979) Immunocytochemistry, Ed. 2, John Wiley and Sons, New York.

Szentagothai, J. (1964) Neuronal and synaptic arrangement in the substantia gelatinosa Rolandi. J. Comp. Neurol. 122: 219239.

Tenen, S. S. (1968) Antagonism of the analgesic effect of morphine and other drugs by $p$-chlorophenylalanine, a serotonin depletor. Psychopharmacology (Berlin) 12: 278-285.

Walberg, F. (1966) Elongated vesicles in terminal boutons of the central nervous system, a result of aldehyde fixation. Acta Anat. (Basel) 65: 224-235.

Yaksh, T. L., and P. R. Wilson (1979) Spinal serotonin terminal system mediates antinociception. J. Pharmacol. Exp. Ther. 208: 446-453.

Yezierski, R. P., T. K. Wilcox, and W. D. Willis (1982) The effects of serotonin antagonists on the inhibition of primate spinothalamic tract cells produced by stimulation in nucleus raphe magnus or periaqueductal gray. J. Pharmacol. Exp. Ther., in press. 